\title{
Treating Offending Children: What Works?
}

\author{
Claire Nee* \\ International Centre for Research in Forensic Psychology \\ University of Portsmouth \\ King Henry Building \\ King Henry I St \\ Portsmouth PO1 2DY
}

\section{Tom Ellis}

Institute of Criminal Justice Studies

University of Portsmouth

St George’s Building 141 High Street

Portsmouth PO1 2HY

* Corresponding author

Legal and Criminological Psychology. (2005) 10, pp. 1-16. 


\begin{abstract}
Purpose There is little evidence on the effectiveness of interventions with offending children and juveniles, either in Europe or North America. We present the evaluation findings of an innovative intervention and relate these to the existing evidence-base for young offenders and to the more extensive literature on older offenders.

Methods Using an established risk predictor (LSI-R), we measured the criminogenic risks and needs of the intervention group and a non-intervention group of child and juvenile offenders at six-monthly intervals. Local police charges data were also collected for both groups as an indicator of offending behaviour.

Results Over the first thirty months of the project, a statistically significant drop was seen in the LSI-R scores of the project participants, with favourable effect sizes. Effect sizes improved markedly with longer-term intervention. There were also strong indications that the level of offending behaviour had decreased during the intervention. The comparison group showed no change in risks, needs or offending rate.

Conclusions We suggest this study provides an important contribution to the evidence-base of 'what works' with child and juvenile offenders and we suggest that an increased focus on understanding effective intervention with very young offenders is required.
\end{abstract}




\section{TREATING OFFENDING CHILDREN:}

\section{WHAT WORKS?}

In recent years in Europe and the USA, attempts to explain, intervene with, and reduce criminality have focussed on increasingly younger offenders. In their review of factors affecting delinquency with the Study Group on Serious and Violent Juvenile Offenders, Loeber and Farrington (1998) concluded that many serious and persistent offenders began their careers well before their teenage years. A second, wide-ranging study group therefore focused on very young offenders, in the first comprehensive attempt to bridge the knowledge gap in this field (Loeber and Farrrington, 2000). It highlighted the fact that the origins of serious, persistent and long-term antisocial behaviour can often be seen in persistent disruptive behaviour from as early as 2 and 3 years of age (Keenan, 2001; Loeber and Farrrington, 2000). This supports the distinction mooted some years earlier between 'life-course persistent' and 'adolescent-limited offenders' (Moffitt, 1993).

The most prolific researchers in this field, Loeber and Farrington (and their co-authors), have stressed that the majority of UK and US resources are spent on adolescent and older offenders and that earlier intervention is both very rare and urgently needed (Loeber and Farrington, 2001; Stouthamer-Loeber and Loeber, 2002). 
There are examples of promising interventions with problematic and antisocial pre-teenage children, some of whom are already offending (Carr, 2000; Tremblay and LeMarquand, 2001; Wasserman and Seracini, 2001). However, these focus on preventing difficult behaviour leading to later delinquency, rather than on children with established offending behaviour. Programmes for persistent child offenders, based explicitly on a risk/needs model of juvenile offending and that incorporate risk/needs predictors in their evaluations, are therefore extremely rare and such programmes have yet to report on their findings (Howell, 2001). Lipsey and Wilson (1998), in their review of published research on serious juvenile offender programmes found that only 4 out of 200 (now rather dated) studies focussed on pre-teenagers and none has been published in the UK. Further, current understanding of 'what works' in reducing criminality is largely based on meta-analyses of interventions with late adolescent and older offenders (see McGuire, 2002 for a review of these meta-analyses). It seems, therefore, there is a very small evidence base on an area should that should reap great benefits in terms of reducing crime and damaged lives (Tremblay and LeMarquand, 2001; Welsh, 2001).

This article presents a relatively small-scale ${ }^{1}$, but important, contribution to what is essentially a gap in criminological literature. Below, we describe the findings of an innovative offending behaviour programme for persistent young offenders, half of whom are aged

\footnotetext{
${ }^{1}$ The study is longitudinal in design and the numbers involved will grow steadily over time.
} 
between 7 and 12, and which utilises a robust risk/needs assessment tool (the LSI-R) as the primary measure of change.

Despite the the paucity of literature on effective interventions with child offenders, there is a large body of work on the risk factors associated with the development of criminality and this provides a useful backdrop for the current project. Longitudinal studies following cohorts of individuals from birth or childhood in the UK (Farrington, 2002), the US (Loeber, Farrington, Stouthamer-Loeber, Moffitt, and Caspi, 1998) and Canada, (Tremblay, Masse, Vitaro and Dobkin, 1995) have provided us with a clear array of factors differentiating those who are likely to embark on a largely antisocial, and therefore potentially criminal life course, with those who are not. Their findings are strongly backed up by reviews of empirical studies of criminality since the 1950s and which, theoretically speaking, support a social learning perspective which combines individual, familial, societal and situational factors (Andrews and Bonta, 1998).

These risk factors have been extensively reviewed elsewhere ${ }^{2}$, and include low IQ, antisocial temperament, birth trauma and criminal history (individual); large family, criminal siblings and poor parenting (familial); poor neighbourhood and academic achievement (societal) and opportunity and immediate risk in committing crime (situational).

\footnotetext{
${ }^{2}$ See Loeber and Farrington (2001, Part II) for an exhaustive account.
} 
Our focus has therefore been on interventions and research instruments that have been underpinned by these findings.

Andrews and Bonta (1995) developed the most prominent of the new generation of criminogenic risk/needs assessment tools, for measuring change in offenders and predicting risk of reoffending. The Level of Service Inventory - Revised (LSI-R, Andrews and Bonta, 1995) operationalises the constellation of risk/needs factors identified in the literature reviewed above and this is the assessment instrument (which we describe in detail below) we used for our evaluation.

\section{The Project}

The Persistent Young Offender Project (PYOP) was set up, in one UK city, in response to the Audit Commission report on reducing criminality in children and young people ('Misspent Youth', 1996). The report recommended more intensive supervision of persistent young offenders and crime prevention work for young people at risk of offending. The criteria for referral and acceptance onto PYOP (in line with Youth Justice Forum recommendations) are therefore as follows:

- Prolific offenders, defined through the national Youth Offending Information System database (YOIS) as anyone with 10 offences in 12 months or anyone facing a custodial sentence

- $\quad$ Offenders with special needs, such as sex offenders

- Preventative/protective referrals for young people between 7-12

The problems of defining the ever-changing criminal policy category of the 'persistent' or 'prolific' young offender are well documented 
(see Hagell and Newburn, 1994). For this project, the children selected were known to be persistently offending by those who referred them. This classification of 'persistent offending' was therefore not wholly reliant on official data (many were too young to hold a criminal record) and intervention was designed to prevent further progression into, and association with, the criminal justice system.

The first innovative feature of the project was that it had no lower age limit and about half of the participants were aged twelve and below. Secondly, participants needed no formal link with the criminal justice system in order to participate, allowing fast, less stigmatising access for children in need. Referrals came from social workers, the local Youth Offending Team (YOT), the Education Department, a local community safety partnership, parents and from participating offenders themselves.

As external and independent evaluators, we recommended, at the start of the project, that the PYOP co-ordinator conduct an initial risk/needs assessment, using LSI-R, on all referrals. These referrals were then accepted or rejected by PYOP based on this and other, social workbased, assessments for children in need. For selected participants, the project coordinator drew up a joint personal programme of interventions, based on individual needs. These examples of sound assessment and allocation to services on the basis of need demonstrated a strong commitment to the 'responsivity principle' 
considered so important in effective interventions with older offenders (Andrews and Bonta, 1998; McGuire and Priestley, 1995).

The assessment process was additionally underpinned by a strong commitment to a multi-system approach (Lipsey, 1995; McGuire and Priestley, 1995). This ensured that PYOP considered the broader needs of the individual offender and required additional assessment and intervention in familial, educational and community arenas ${ }^{3}$. The few promising interventions for pre-teenage offenders in North America (see Howell, 2001 for a description) have taken a similar approach. In particular, the Under-12 Outreach Project in Toronto has a commendably broad-ranging approach, and an evaluation of its effectiveness is under peer review (Augimeri, Farrington, Koegl and Day, 2003).

The 'core intervention resources toolbag' used by PYOP is also multimodal, based on existing evidence of effective interventions (Andrews and Bonta, 1998; Loeber and Farrington, 2001). In particular, the key elements of the most successful programmes (identified in a metaanalysis of 117 interventions with non-institutionalised teenage offenders over the last 40 years by Lipsey and Wilson, 1998) are well reflected in PYOP intervention, ie, interpersonal skills; individual

\footnotetext{
${ }^{3}$ Only 'Intermediate Treatment' programmes in the 1970's compare with this approach and were aimed at improving the general situation of the young offender. However, they were not based on any detailed analysis of needs (see Haines and Drakeford, 1999, for a review).
} 
counselling ${ }^{4}$; multi-modal and cognitive-behavioural programmes. There is also evidence that the most successful interventions with troubled children require parental involvement (Gordon, 2002; Wasserman and Seracini, 2001).

PYOP intervention therefore includes: one-to-one mentoring for reintegration into education, anger management and constructive use of time. There is group-work for: antisocial behaviour; problem-solving; anger management; victim awareness; interpersonal skills; substance misuse; appropriate sexual behaviour; and health issues. There are also music, art and drama workshops plus challenging outdoor activities to develop self-esteem and social skills. Siblings are welcome at most of these provisions, and counselling and referral are available to parents.

In contrast to the way standard accredited programme interventions are administered to young and adult offenders by the Youth Offending Teams, or prison and probation services in England and Wales (Crow, 2001), there was no standard dosage/intervention formula for PYOP participants. Rather, continual assessment of risks and needs and continuing disclosure were used (along traditional casework lines) to constantly refine and change the level and types of individual intervention - another example of responsivity. If needs were identified

\footnotetext{
${ }^{4}$ It is interesting and important that structured individual counselling appears more effective with serious juvenile offenders (Lipsey and Wilson, 1998) than young offenders in general (unstructured counselling was ineffective with both groups, Lipsey, 1995). This may be due to clearer emotional need in more serious offenders, who are more likely to be from a 'life course persistent' offending population. Some caution is required with Lipsey and
} 
that could not be addressed from core resources, then extra services were bought in or developed in house. Moreover, the type and dosage of interventions were continually adjusted over time, depending on changing need, again, unlike standard accredited programmes.

Each participant's case was reviewed every 8 weeks, with a more formal review (including collection of evaluation data) every 6 months. However, participants were continually monitored by the project coordinator who received at least weekly feedback from those observing the participants, including police officers, parents, schools, socialworkers and programme workers.

\section{Methods}

\section{Participants}

PYOP has supervised over 150 offenders to date, but most stayed with the project for only 6 months. This article however, focuses on the 41 aged between 7 and 16 who received more than 6 months of intervention, and have therefore been assessed for evaluation measures at least twice. Half of these offenders were aged between 7 and 12 . This approach has allowed us to measure the impact of a small, intensive project such as PYOP in a quantitative and robust way and

Wilson's (1998) findings however, in that the most effective interventions were based on a very small number of studies, which are now quite dated. 
also to provide feedback on its effectiveness to the coordinator and sponsors.

The background characteristics of the group are typical of those associated with young offending generally (Farrington, 2002; Loeber et al, 1998). Forty of the 41 were male and although ethnicity was not collected systematically we know that 37 were white. There was a high degree of: school exclusion (only 5 of the 41 had not been excluded and they were all under 13); experience of local authority childrens' accommodation; drug and alcohol misuse; inclusion on the Child Protection Register. A proportion had also served custodial sentences.

Instrumental or 'volume' crime, typically involving property, was very heavily represented (over half the sample had theft, shoplifting, burglary and/or car theft as one of their current alleged offences), but so were other more expressive offences. A third had been involved in criminal damage and assault, including two very young offenders (aged 11 and 12) who had allegedly been involved in armed robbery and arson respectively. Importantly, while research on interventions with offenders aged 12 and upwards has typically focussed on property crime (Lipsey and Wilson, 1998), 6 of the 41 participants evaluated had allegedly committed sex offences, including rape and indecent assault. 


\section{Comparison with a non-intervention group}

It is difficult to compare intervention results with outcomes from offending children from similar backgrounds and age-groups who had no intervention. Along with the project coordinator, we created a comparison group of young people referred, assessed and accepted onto the project, but who dropped out within the first 2 weeks (an 'incidental' matched group, Marshall and McGuire, 2003). These offenders were then reassessed 6 months later. Constructing comparison groups is always problematic and it could be argued that these offenders represented a more risky subset, simply because they dropped out of the project. However, they were very similar in age, background and eligibility for the project and did not have significantly worse LSI-R scores at the start of the project ${ }^{5}$. The nonintervention group was relatively small $(n=19)$ at the time of the current analysis.

\section{Measures}

1. 'LSI-R' as an assessment and evaluation tool. Since PYOP has an overriding aim to reduce re-offending among persistent young offenders, we suggested the use of the LSI-R (Andrews and Bonta, 1995) from the outset of the project. Though relatively new to the UK, LSI-R is currently one of the most common risks/needs instruments

\footnotetext{
${ }^{5}$ Mean $=19.0$ (comparison group) and 17.5 (intervention group), $\mathrm{p}=0.266$ ), indicating that the two groups had similar risks of re-offending at Time 1.
} 
used with offenders in England and Wales and has been used extensively for many years in a wide variety of settings in the US and Canada (see Andrews and Bonta, 1998, for a review). One of the third generation of 'complex’ risk predictors (Hollin, 2002), it successfully brings together both static (e.g. criminal history) and dynamic (e.g. attitudes to offending, personal distress) criminogenic risk factors making it a more flexible tool than its more simple predecessors that measured these aspects separately.

Perhaps most importantly for the evaluation of PYOP however, the LSI-R has been shown to be highly predictive of future offending in reconviction studies both in the US (Gendreau, Little and Goggin, 1996; O’Keefe, 1997) and here in Britain (Raynor, Kynch, Roberts and Merrington, 2000) albeit with older offenders than in our project. Its 10 sub-components reflect the most prominent risk factors associated with recidivism in the empirical literature, including the 'big four': antisocial associates; attitudes; personality; and criminal history (Andrews and Bonta, 1998). It is certainly considered to have the strongest 'research pedigree' of risk predictors currently available and is currently the only risk predictor to be grounded in a comprehensive theoretical perspective (Hollin, 2002). These features are extremely important in the context of PYOP because about half of its participants are below the age at which they can be entered into a 
formal reconviction study ${ }^{6}$. Without the opportunity to carry out a reconviction study on a large proportion of our participants, it was of paramount importance that we used the highest quality risk predictor in order to measure the impact of the intervention.

While LSI-R has yet to be standardised for offenders under the age of $17^{7}$, it has been used successfully with offenders on probation aged 17 and over (Raynor, 1998). A new version for young people (the Youth Level of Service Inventory or YLSI; Hoge and Andrews, 2002) has been published since PYOP evaluation commenced, but has not yet been validated in relation to reoffending in the $\mathrm{UK}^{8}$.

2. Measuring change in the sub-components of the LSI-R.

For each participant, LSI-R assessment was repeated every 6 months. Changes in the overall score are a valuable, relatively objective guide to changes in the offender's risk of re-offending, and changes in the dynamic sub-components give a clear indication as to where change is occurring. Examining change in this way is an important and innovative use of the LSI-R from both the evaluators' and practitioners’ perspective. As Hollin (2002) notes, research addressing differences in risks and needs amongst different offending populations is crucial as we move into a further, more sophisticated, phase of 'what

\footnotetext{
${ }^{6}$ The Home Office algorithm (OGRS2) used in UK reconviction studies does include children from age 12 upwards, but not in sufficient numbers to generate a representative comparison group. Clearly, children under 10 cannot have an official criminal record in the UK, and most aged between 10 and 12 do not have one, even if offending.

${ }^{7}$ This will rely on larger samples of different age groups as time progresses.

${ }^{8}$ Though studies are beginning to emerge in the US (Ilacqua, Coulson, Lombardo and Nutbrown, 1999).
} 
works' investigations. To date, LSI-R sub-component analysis has only been carried out by Raynor et al (2000) and Hollin, Palmer and Clark (in press) in relation to establishing the predictive reliability and validity of the instrument (in relation to adult probationers and prisoners respectively), and by ourselves in the current evaluation context. It also underlines the LSI-R's heightened versatility in comparison to other complex risk predictors, such as the Psychopathy Checklist - Revised (Hare, 1991).

3. Police charges data. Traditional reconvictions analysis, using the Home office algorithm (OGRS2 - Home Office, 1993) as a measure of intervention impact, is of limited value in relation to PYOP. Around half of the project's participants are aged below 12 and, even if known to the police, many (aged 10 and over) may have simply been charged and received warnings rather than convictions. Loeber and Farrington (2001) have noted the reluctance of police and sentencers to criminalise very young offenders by convicting and sentencing them, leaving official data for this category of offender even more incomplete and unreliable than for older offenders.

As a proxy for offending behaviour and recidivism for those aged 10 and over, we collected data on local police charges for the six months before participation with the project and compared it to the six months following first contact with PYOP. This allowed us to match 'reoffending' more directly to the periods of measurement we used for 
LSI-R. While these charges data are important, they should be treated with more caution than LSI-R scores (which themselves take 'reconvictions' into account), as they can suffer from either incompleteness (ie the offence is not discovered) or from overinclusion (ie, the vast majority of charges did not result in a conviction and were either dropped or resulted in a warning).

Use of LSI-R data and police charges data constitute what Pawson (1997) describes as a 'black box' approach to the evaluation. We focussed first on the inputs and outcomes of a project, to evaluate whether or not the project is achieving its overall aims (in this case reducing re-offending). If successful on these measures, this justifies an additional process evaluation ('grey box') to identify how and why the project is working. Again, this approach contrasts strongly with the approach taken for the implementation of accredited programmes for the prison and probation services.

\section{Results}

\section{Results of the LSI-R Analysis}

Our results are based on the first 30 months of the project, focussing on LSI-R and police charges data of 41 participants (Group1) and the comparison group of 19 (Group 2). The primary aim of the analysis was to assess the impact of PYOP on overall LSI-R measures between Time 1 (initial assessment) and Time 2 (6 months later) for the 
intervention group, and to compare these with the non-intervention (comparison) group.

Given the wide age range (7 to 16 ), we also thought it important to check for the effect of age on PYOP's impact. We undertook a 2(time) x 2 (group) ANCOVA with age as a covariate. We found a significant interaction between time and group $(F(1,57)=10.51, p=0.002)$ and a significant effect of the covariate age $(F(1,57)=5.95, p=0.01)$. Subsequent analysis of the group variable at the two time points, adjusted using Bonferroni's t-test, found no significant difference between the intervention and comparison group at Time $1(p=0.973)$ but a significant difference at Time $2(\mathrm{p}=0.039)$. Figure 1 illustrates this graphically and indicates that PYOP was having a significant, positive effect on the intervention group at the six-month time point, while the comparison group's scores worsened. The effect size (etasquared) was 0.16 , which compares very favourably with previous studies on the impact of interventions for juvenile offenders on recidivism. Effect sizes for the majority of these ranged from 0.12 to 0.13 (e.g. Gottschalk, Davidson II, Gensheimer, and Mayer, 1987; Kaufman, 1985; Whitehead and Lab, 1989). In fact, Lipsey’s metaanalysis of 443 studies of juvenile offenders yielded treatment effects of between 0.05 and 0.08 . Stronger treatment effects have been seen in adult offenders (McGuire, 2002) but these still range from 0.10 to 0.29. While effect sizes, including those of PYOP, may seem small at face value, it is important to remember that they compare very 
favourably to what are considered to be strong effect sizes in medical research (Marshall and McGuire, 2003; McGuire, 2002).

In terms of the effect of age, the raw data indicated that older participants were benefiting more from PYOP’s intervention, though this should be viewed with some caution as the older participants generally had higher LSI-R scores at the start and therefore had more room to improve.

Figure 1 Estimated marginal means of LSI-R at Times 1 and 2 for Intervention and Comparison Group

As with any intervention programme, a few participants did not change in a positive direction i.e., their overall LSI-R scores did not decrease over the six month period. Nine out of 41 participants increased their risk scores, though for 6 the change was negligible (2 points). One (YP13), who increased by three points, was engaging well with education but living in very difficult conditions and selfharming. Two had dramatic rises: YP34 increased from 24 to 32 (and later went to a Local Authority Secure Unit) and YP62 increased from 11 to 22 before dropping out of the project. 
Table 1 lists the means and standard deviations of all LSI-R subcomponents and indicates in bold where significant change occurred ${ }^{9}$. As all our participants were of school age, we analysed the dynamic education items of the Education/Employment sub-component (items 18, 19 and 20) separately, as clearly, the employment items were of little relevance to them.

Table $1 \quad$ Comparison of LSI-R sub-scores at Time 1 and Time 2: Indicating areas of significant improvement

PYOP appears to have made its greatest impact in four areas. First, on the recreation sub-component, more specifically 'participation in an organised activity' and 'good use of time'. Second, on the dynamic education items of Education/Employment reflecting engagement with education, including attitudes towards peers and authority figures while at school. The latter is a remarkably positive finding given the high level of school exclusion prior to PYOP. The significant improvement in (family) financial problems also highlights the importance of using a broad, multi-modal approach to offenders' needs.

Finally, a significant improvement in criminal attitudes and orientation is obviously what the project set out to achieve and appeared to be having an impact. Emotional/personal problems and general family

\footnotetext{
${ }^{9}$ It is worth noting that the means relating to the sub-component 'Criminal History' have significantly increased. This is due to increased disclosure of previous offences over time. This static sub-
} 
problems were also approaching significant improvement. Metaanalyses of studies of recidivism in adult offenders have shown antisocial attitudes, antisocial peers and antisocial personality to be most predictive of future re-offending ${ }^{10}$, followed by family problems, education and employment (Andrews and Bonta, 1998; Gendreau, Little and Goggin, 1996). It is important to note, therefore, that PYOP intervention appeared to be affecting positive change in these areas with persistent child offenders, although the configuration of impact may be somewhat different.

Research with adult offenders has shown that longer intervention with offenders indicates an increased chance of preventing relapse (Raynor, 1998). However, it is unusual for treatments of juvenile offenders to last more than 30 weeks (Lipsey and Wilson, 1998). PYOP has a longterm approach (offenders can be involved for as long as they feel it is necessary) that again, is innovative. Over the evaluation period, 22 of the 41 young people in Group 1 had been engaging with the project for over a year (half of whom are aged 12 or under). A repeated measures univariate ANOVA with this group of 22 (Group 2) also indicated a statistically significant drop in risk scores on the LSI-R after 1 year (Time 3) of PYOP intervention $(F=14.56, p<0.001)$. However, pairwise comparisons showed a significant change between Times 1 and 2 (after 6 months), and Times 1 and 3 (after 1 year), but not between Times 2 and 3 (from after 6 months to 1 year). This indicates 
that the positive impact achieved by PYOP was greatest in the first six months, but, importantly, was maintained over time. Further, the effect size of this impact was 0.54 , which is considerably larger than that of previous research in this field (see above).

Figure 2 Estimated marginal means of LSI-R at Times 1, 2 and 3.

A closer look at the sub-component data indicates that PYOP was making an impact in a greater number of problem areas with Group 2 at Time 3 (after a year of PYOP). As well as those sub-components included in Table 1 above, there was evidence that emotional/personal problems $(t=3.68, p=0.002)$, accommodation problems $(t=2.33, p=$ $0.031)$ and broader family problems $(t=2.26, p=0.035)$ significantly improved. It is also interesting that three quarters of Group 2 were aged under-13 (as opposed to half in Group 1), indicating PYOP's facility for early, long-term engagement with very young offenders.

Results of the police charges data analysis

Data was available for all of the 35 offenders aged 10 and over in Group 1 and all 19 members of the comparison group. Two 'outliers'11 from Group 1 who had dramatic increases in the number of charges against them during this period were removed from the analysis leaving $\mathrm{n}=33$ for Group 1 . A mixed factorial ANOVA was carried out

${ }^{10}$ Criminal history is also highly predictive, but as we have already seen, this is retrospective and cannot improve over time. 
comparing police charges for the two groups for the 6 months before PYOP started with the first 6 months during PYOP. A significant interaction was found between time and group $(F(1,50)=6.77, p=$ 0.01) indicating a significantly greater reduction in police charges in PYOP Group 1 compared to the comparison group (see Figure 3). Post hoc comparisons (using Bonferroni's t-test) again showed no significant difference between the groups at Time $1(t=-1.05, p=$ 0.29), but a significant reduction for the PYOP group at Time $2(t=-$ 3.57, $p=0.001)$. The effect size here was similar to the LSI-R analysis at 0.12 , comparing favourably with previous research.

Figure 3 Estimated marginal means of Police Charges data at Times 1 and 2, for Intervention and Comparison Group

According to schools and project workers who were seeing participants often on a daily basis, the remaining 6 members of Group 1 who were under the age of 10 had stopped offending during PYOP intervention. Other behaviour was sometimes still reported as problematic but offending had reportedly stopped.

The raw charges data suggested that around $70 \%$ of Group 1 had either reduced their level of offending $(n=16)$ or had not been charged/reoffended at all while on the project $(n=13)$. The 10 remaining participants (once the 2 outliers were excluded) showed only marginal

\footnotetext{
${ }^{11}$ One was an 11 year old armed robber who remained with PYOP for a year and whose charges increased during the time period from 3 to 43 and who ended up in custody for assault. The second
} 
change. While it could be argued that the charges data alone are a relatively 'soft' additional indicator of the impact of the project, when combined with the LSI-R analysis, and the results from the comparison group, they strongly suggest that the PYOP intervention is successful.

Just as important as magnitude when assessing recidivism are: the comparative seriousness of future crimes; the temporal clustering of crimes; and the distance in time from intervention to the next offence (Lloyd, Mair and Hough, 1994; Mair and Nee, 1992). With the exception of 2 participants in Group 1, all charges once intervention had begun were for minor property crimes, suggesting no increase in the seriousness of offending. When we compared the police charges data (for ages 10 and over) and reported re-offending data (for the under-10's) to changes in the LSI-R scores, we found that these correlated well with each other. Of the 26 who had reduced their LSI-R scores: 12 had not ostensibly re-offended at all while on the project; 4 had negligible charge 'rates' (between 1 and 3 charges either before or during PYOP); and 7 reduced their charge rates. Only 3 of this 26 had either increased their charges rate or maintained the same high charge rate. Similarly, of the 3 who had increased their LSI-R scores over the first 6 months of PYOP (ie, at Time 2), 2 (the outliers mentioned above) had dramatically increased the charges against them. The third of these offenders had reduced the number of charges from 6 to 2, but unfortunately the type of charge had increased in seriousness from theft to robbery. However, the general trend 
in offending behaviour change strongly reflects the changes in the LSI-R scores and again underlines its robustness in predicting future offending.

Alongside charges data, our assessment of re-offending in the future is likely to include a calendar method of self-reported offending with the younger age-group as a more robust way of measuring actual offending behaviour before, during and after intervention (see Horney, in press; Lewis and Mhlanga, 2001; and Nee, 2003; for examples of how useful this method can be with adult offenders). This triangulated approach should provide us with a comprehensive measure of the impact of the programme. It will provide the project with more sound evidence of effective practice than most probation services (see Ellis and Underdown, 1998), or for that matter, the Youth Justice Board, can provide.

\section{Discussion}

This evaluation focussed on an analysis of the criminogenic needs and risks of reoffending (using LSI-R scores) and also on police charge data. It also takes into account information from other professionals, such as teachers, as a proxy for re-offending behaviour, both before and during the project. The results over its first 30 months of intervention are very encouraging. There are significantly reduced risks, improved needs indicators, and greatest impact where there is longer-term intervention. The findings on the rate, frequency and 
seriousness of re-offending are also promising. These positive results all contrast clearly with the comparison group, where there was no change. As already noted, robust evidence of successful intervention with adolescent offenders is rare and with pre-teenage offenders is exceptionally rare (Howell, 2001; Lipsey and Wilson, 1998).

It is important to note that PYOP satisfies the vast majority of McGuire and Priestley’s (1995) criteria for effective programmes for older offenders, indicating that these may also be the key to successful intervention with much younger offenders. First, in relation to criminogenic risks and needs classification, all the participants are persistent young offenders and their LSI-R scores show that they have relatively high risks and needs. Second, (and unlike typical cognitivebehavioural programmes for adult offenders) PYOP can be described as truly 'responsive' to the individual needs of its participants, not only at initial assessment, but also in changing the nature and intensity of intervention in response to changing needs (including disclosure) over time. Third, McGuire and Priestley (1995) suggested that communitybased interventions might be superior to custodial-based interventions in reducing recidivism. The evidence since has been mixed on this. While Lipsey's (1995) meta-analysis of 400 young offender programmes supports McGuire and Priestley, later analysis of juvenile offenders (Lipsey and Wilson, 1998) found equally strong effects for successful custodial and non-custodial programmes. It is clear, however, that more punitive, deterrence-based programmes failed in 
both contexts. Recent evaluations of such custodial disposals (Secure Training Orders) for 12-14 year olds, with very similar risk profiles to those on PYOP, show high rates of reoffending upon release (Hagell, Hazel and Shaw, 2000). It seems, therefore, especially appropriate to deal with pre-teenage offenders in non-custodial settings, and the results of PYOP suggest this can be done effectively, perhaps as an alternative to high-tariff Intensive Supervision and Surveillance Programmes.

While these general 'what works' principles have been upheld, we still need to know more about how and why this intervention is effective in reducing offending in such young offenders. In contrast to the implementation of accredited programmes in probation and prisons, our 'black box' approach has been outcome-led. We looked for evidence of success first, rather than attempting to affect the nature of the intervention. What remains is to assess the remaining two 'what works' principles: treatment modality and programme integrity, to produce a 'grey box' evaluation which combines process and outcome (Pawson, 1997). In other words, now we know that PYOP works, it now remains for us to establish why.

We have already esatablished that the content of the programme incorporates the limited empirical evidence on effective practice with young teenage offenders (Lipsey and Wilson, 1998). The programme is multi-modal in that it teaches cognitive, behavioural and 
interpersonal skills, and combines these with a wide variety of other approaches which address the broader needs of offenders and their families. The content and techniques, plus dosage and other factors will be investigated thoroughly in the next part of the evaluation.

Our approach has shown that the LSI-R can be used very effectively with very young offenders. We have highlighted why it is particularly important to find a reliable risk predictor with this age group in comparison to older offenders. The results also provide support for the social-learning theory upon which the instrument is based (Andrew and Bonta, 1994). More specifically, the risk/needs areas in which we saw most impact with PYOP's participants were: constructive recreation; attitudes and engagement with education; (parent's) financial problems; and criminal attitudes and motivation. Those participating for more than a year also saw improvement in: emotional problems; accommodation problems; and broader family problems.

\section{Conclusion}

While we know a considerable amount about the risk factors contributing to the development of criminality in the early years, we are clearly in the infancy of knowing 'what works' with child offenders. For instance, should interventions address all types of risk factors equally or will some have greater impact? We have already seen differences in the treatment modes of effective programmes 
between serious, persistent young offenders and their less problematic criminal counterparts (Lipsey, 1995; Lipsey and Wilson, 1998). There is some suggestion in our work that emotional needs may be particularly important in child offenders. Can 'persistent voluntary participation' be assured in place of persistent offending and mandatory court orders? Will the approach continue to be as effective for both the 'non-specialist' majority of persistent offenders and those who persist with only a narrow band of crimes, such as sex offenders? Since PYOP is to be funded for at least another 3 years, this should provide a rare and valuable opportunity to begin to answer some of these questions over an extended period of time as participant numbers grow. It will hopefully be supplemented by other studies of a similar design, and by an increased acknowledgement of the importance of early intervention to avoid persistent criminality and involvement with the formal criminal justice process.

The authors would like to acknowledge the help of Rhona Lucas and her staff, Darren Van Laar and Aldert Vrij. 


\section{REFERENCES}

Andrews, D.A. \& Bonta, J. (1998). The Psychology of Criminal Conduct, Cincinnati: Anderson.

Andrews, D. A. \& Bonta, J. (1995). The Level of Service InventoryRevised, Toronto: Multi-Health Systems Inc.

Aubrey, R. \& Hough, M. (1997). Assessing offenders' needs: assessment scales for the Probation Service. Home Office Research Study No 166. London: Home Office.

Audit Commission (1996). Misspent Youth. London: HMSO.

Augimeri, L., Farrington, D. P., Koegl, C. \& Day, D. (2003). A community based programme for children with conduct problems: immediate and longterm effects. Submitted for peer review.

Carr, A. (Ed.) (2000) What Works with Children and Adolescents: A Critical Review of Psychological Interventions with Children, Adolescents and their Families. London: Routledge.

Crow, I. (2001). The Treatment and Rehabilitation of Offenders. London: Sage.

Ellis, T. \& Underdown, A. (1998). Evaluation and the Evidence Base. (Chapter 9). In Strategies for effective offender supervision: Report of the HMIP What Works Project. London: HMIP.

Farrington, D. P. (2002). Developmental criminology and riskfocussed prevention. In M. Maguire, R. Morgan \& R. Reiner (Eds), The Oxford Handbook of Criminology, (3rd Ed.) Oxford: Oxford University Press. 
predictors of adult offender recidivism: what works! Criminology, 34, 575-607.

Gordon, D. (2002). Intervening with families of troubled youth: functional family therapy and parenting wisely. In J. McGuire (Ed.). Offender rehabilitation and treatment: effective programmes and policies to reduce re-offending. Wiley: Chichester.

Gottschalk, R., Davidson II, W. S., Gensheimer, L. K.\& Mayer, J. P. (1987).Community based interventions. In H.C. Quay (Ed). Handbook of Juvenile Delinquency. New York: Wiley, 266-289.

Hagell, A., Hazel, N. \& Shaw, C. (2000). Evaluation of Medway Secure Training Centre. London: Home Office

Hagell, A. \& Newburn, T. (1994). Persistent Young Offenders. London: Policy Studies Institute/HMSO.

Haines, K \& Drakeford, M. (1999). Young People and Youth Justice. NewYork: Macmillan.

Hare, R. D. (1991). The Hare Psychopathy Checklist (Revised). Toronto: Multi-Health Systems.

Hoge, R. D. \& Andrews, D. A. (2002). The Youth Level of Service Inventory. Toronto: Multi-Health Systems Inc.

Hollin, C. R. (2002). Risk-needs assessment and allocation to offender programmes. In J. McGuire (Ed.). Offender Rehabilitation and Treatment: Effective Programmes and Policies to Reduce Re-offending. Chichester: John Wiley and Sons.

Hollin, C. R., Palmer, E. J. \& Clark, D. (in press). The Level of Service Inventory - Revised profile of English prisoners: a needs analysis. Criminal Justice and Behaviour. 
Home Office (1993). The National Risk of Reconviction Predictor.

London: Home Office Research and Planning Unit.

Horney, J. (In press). Criminal events and criminal careers. In R.

Meier, L. Kennedy \& V. Sacco (Eds.). The Process and Structure of Crime: Criminal

Events and Crime Analysis. New Brunswick, N.J.: Transaction Publishers.

Howell, J. (2001). Juvenile justice programs and strategies. In R.

Loeber. \& D. P. Farrington (Eds). Child Delinquents: Development, interventions and service needs. Thousand Oaks, CA: Sage.

Ilacqua, G. E., Coulson, G. E., Lombardo, D. \& Nutbrown, V.

(1999).Predictive validity of the Youth Offender Level of Service Inventory for criminal recidivism of male and female offenders. Psychological Reports, 84, 3, 2, 1214-1218.

Kaufman, P. (1985). Meta-analysis of juvenile delinquency programs.

Unpublished Master’s thesis. Claremont Graduate School.

(Results reported in Lipsey, 1988).

Keenan, K. (2001). Uncovering preschool precursors to problem behaviour. In R. Loeber \& D. P. Farrington D. P. (Eds). Child Delinquents: Development, interventions and service needs. Thousand Oaks, CA: Sage.

Lewis, D. \& Mhlanga, B. (2001). A life of crime: the hidden truth behind criminal activity. International Journal of Market Research, 43, 2, 217-240.

Lipsey, M. W. (1995). What do we learn from 400 research studies on the effectiveness of treatment with juvenile delinquents? In J. McGuire (Ed.), What Works: Reducing Reoffending (pp 63-78), Chichester: John Wiley \& Sons.

Lipsey M. W. \& Wilson, D. B. (1998) Effective intervention for serious juvenile offenders: a synthesis of research. In R. Loeber, \& D. P. Farrington D. (Eds). Serious and violent juvenile offenders: risk factors and successful interventions. Thousand Oaks, CA: Sage. 
Lloyd, C., Mair, G. \& Hough, M. (1994). Explaining Reconviction Rates: A Critical Analysis. Home Office Research Study 136. London: HMSO.

Loeber, R. \& Farrington D. P. (1998). (Eds). Serious and Violent Juvenile Offenders: Risk Factors and Successful Interventions. Thousand Oaks, CA: Sage.

Loeber, R. \& Farrington, D. P. (2000). Young children who commit crime: epidemiology, developmental origins, risk factors, early interventions and policy implications. Development and Psychopathology, 12, 737-762.

Loeber, R. \& Farrington D. P. (2001). (Eds). Child Delinquents: Development, interventions and service needs. Thousand Oaks, CA: Sage.

Loeber, R., Farrington, D.P., Stouthamer-Loeber, M. Moffitt, T. \& Caspi, A. (1998). The development of male offending:key findings from the first decade of the Pittsburgh Youth Study. Studies on Crime and Crime Prevention, 7, 141-71.

McGuire, J. (2002). Criminal sanctions versus psychologically-based interventions with offenders: a comparative empirical analysis. Psychology, Crime and Law. 8, 183-208.

McGuire. J. \& Priestley, P. (1995). Reviewing what works: past present and future. In J. McGuire (Ed.). What Works: Reducing Reoffending. Guidelines from Research and Practice. Chichester: John Wiley and Sons.

Mair, G. \& Nee, C. (1992) Day Centre Reconviction Rates. British Journal of Criminology. 32, 329-339.

Marshall, W. L. \& McGuire, J. (2003). Effect sizes in the treatment of sexual offenders. International Journal of Offender Therapy and Comparative Criminology, 47, 653-663.

Moffitt, T. E. (1993). Life-course-persistent and adolescence-limited 
antisocial behaviour: a developmental taxonomy. Psychological Review, 100, 674-701.

Nee, C. (2003). The offender's perspective on crime: methods and principles in data collection. In A. Needs \& G. Towl (Eds.), Applying Psychology to Forensic Practice. London: BPS.

O’ Keefe, M. (1997). Validation of the Level of Service Inventory for community based offenders in Colorado. Denver: Department of Corrections.

Pawson, R. (1997). Evaluation methodology: Back to basics. In G. Mair, Evaluating the effectiveness of community penalties. Aldershot: Avebury.

Raynor, P. (1998). Implementing the Level of Service InventoryRevised in Britain: Report 3: Risk and Need Assessment in the Five Pilot Areas, Dinas Powys: University of Wales, Swansea and Cognitive Centre Foundation.

Raynor, P., Kynch, J., Roberts, R., \& Merrington, S. (2000). Risk and Need Assessment in Probation Services: An Evaluation. Home Office Research Study 211. London: Home Office.

Stouthamer-Loeber, M., \& Loeber, R. (2002). Lost opportunities for intervention: undetected markers for the development of serious juvenile delinquency. Criminal Behaviour and Mental Health, 12, 69-82.

Tremblay, R. E. \& LeMarquand, D. (2001). Individual and protective risk factors. In R. Loeber \& D. P. Farrington D. P. (Eds). Child Delinquents: Development, interventions and service needs. Thousand Oaks, CA: Sage.

Tremblay, R.E., Masse, L. C., Vitaro, F. \& Dobkin, P. L. (1995). The impact of friend's deviant behaviour on early onset of delinquency: longitudinal data from 6 to 13 years of age. Development and Psychopathology, 7, 649-668.

Wasserman, G. A. \& Seracini, A. M. (2001). Family risk factors and 
interventions. In R. Loeber \& D. P. Farrington D. P. (Eds). Child Delinquents: Development, interventions and service needs. Thousand Oaks, CA: Sage.

Welsh, B. C. (2001). Economic costs and benefits of early developmental prevention. In R. Loeber \& D. P. Farrington D. P. (Eds). Child Delinquents: Development, interventions and service needs. Thousand Oaks, CA: Sage.

Whitehead, J. T. \& Lab, S. P. (1989). A meta-analysis of juvenile correctional treatment. Journal of Research in Crime and Delinquency, 26, 276-295. 
Table 1. Comparison of LSI-R sub-scores at Time 1 and Time 2: areas of significant improvement are emboldened.

Paired samples t test

\begin{tabular}{|c|c|c|c|}
\hline & Means (SD) & $\mathbf{t}$ & $\begin{array}{c}\text { Significance } \\
\text { (2-tailed) }\end{array}$ \\
\hline $\begin{array}{c}\text { Overall } \\
\text { LSI-R } \\
\text { Score }\end{array}$ & $\begin{array}{l}\text { T1 } 17.48 \text { (8.5) } \\
\text { T2 } 14.53(8.6)\end{array}$ & 3.6 & 0.001 \\
\hline $\begin{array}{l}\text { Constructive } \\
\text { recreation }\end{array}$ & $\begin{array}{l}1.73(0.54) \\
0.82(0.86)\end{array}$ & 6.5 & $<0.001$ \\
\hline $\begin{array}{l}\text { Attitudes/engagement } \\
\text { with education } \\
\text { (dynamic) }\end{array}$ & $\begin{array}{l}2.46(0.89) \\
1.65(1.31)\end{array}$ & 4.12 & $<0.001$ \\
\hline Financial problems & $\begin{array}{l}0.29(0.51) \\
0.12(0.33)\end{array}$ & 2.87 & 0.007 \\
\hline $\begin{array}{c}\text { Criminal } \\
\text { attitudes/orientation }\end{array}$ & $\begin{array}{l}1.90(1.35) \\
1.29(1.6)\end{array}$ & 2.69 & 0.01 \\
\hline $\begin{array}{c}\text { Emotional/personal } \\
\text { problems }\end{array}$ & $\begin{array}{l}0.65(0.61) \\
0.46(0.63)\end{array}$ & 1.94 & 0.06 \\
\hline Criminal history & $\begin{array}{l}2.39(1.90) \\
2.68(2.22)\end{array}$ & -2.21 & 0.03 \\
\hline $\begin{array}{l}\text { Education/ } \\
\text { Employment }\end{array}$ & $\begin{array}{l}0.95(0.49) \\
1.00(0.63)\end{array}$ & -0.70 & 0.48 \\
\hline Family problems & $\begin{array}{l}1.87(1.00) \\
1.63(0.96)\end{array}$ & 1.81 & 0.07 \\
\hline Accommodation & $\begin{array}{l}1.24(0.94) \\
1.14(0.93)\end{array}$ & 1.00 & 0.32 \\
\hline Offending peers & $\begin{array}{l}2.12(1.5) \\
2.14(1.49)\end{array}$ & -0.19 & 0.85 \\
\hline $\begin{array}{l}\text { Drugs/alcohol } \\
\text { problems }\end{array}$ & $\begin{array}{l}1.53(2.34) \\
1.43(2.08)\end{array}$ & 0.44 & 0.66 \\
\hline
\end{tabular}


Figure 1 Estimated marginal means of LSI-R at Times 1 and 2 for Intervention and Comparison Group

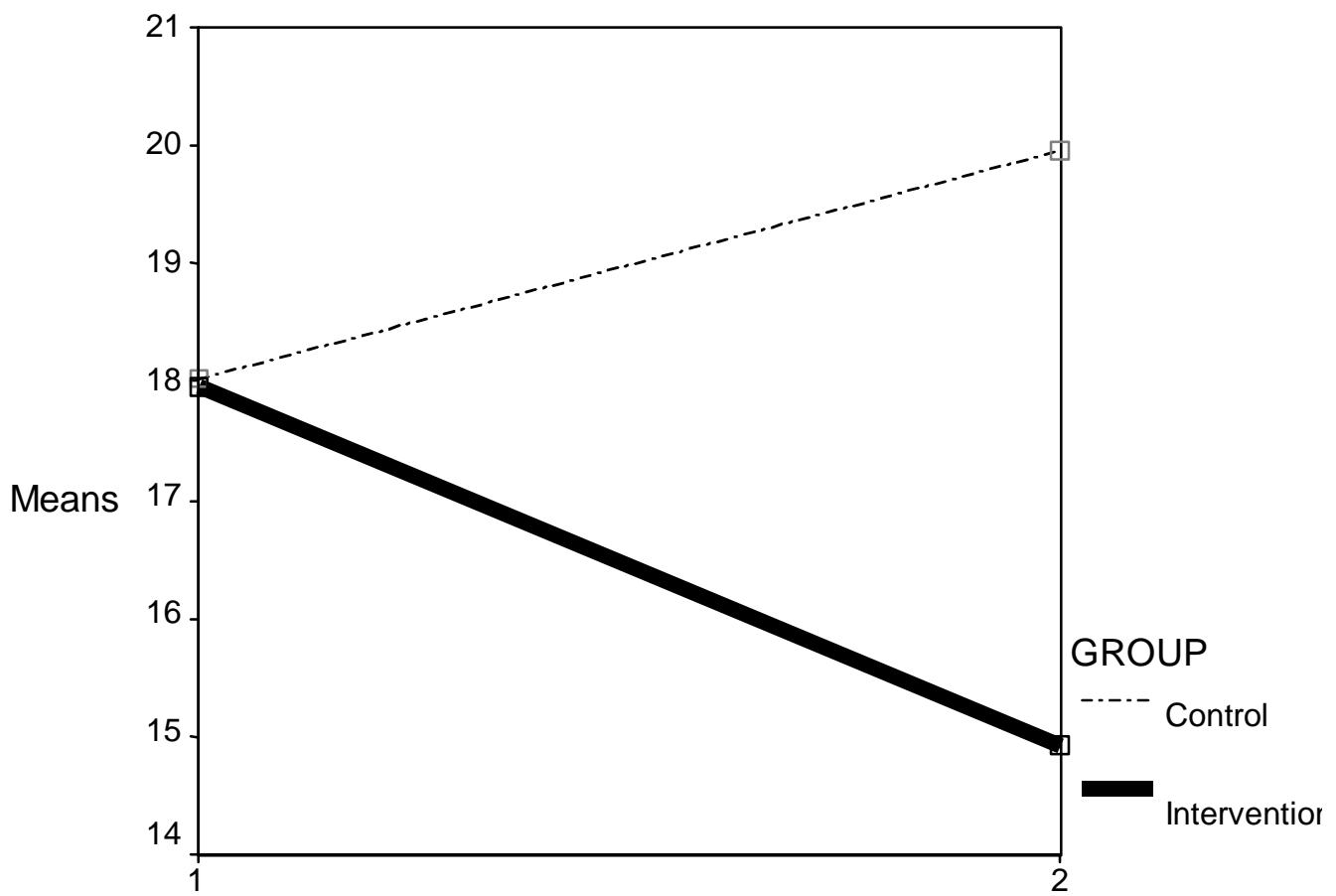

TIME EFFECT WITH AGE PARTIALLED OUT 
Figure 2 Estimated marginal means of LSI-R at Times 1, 2 and 3.

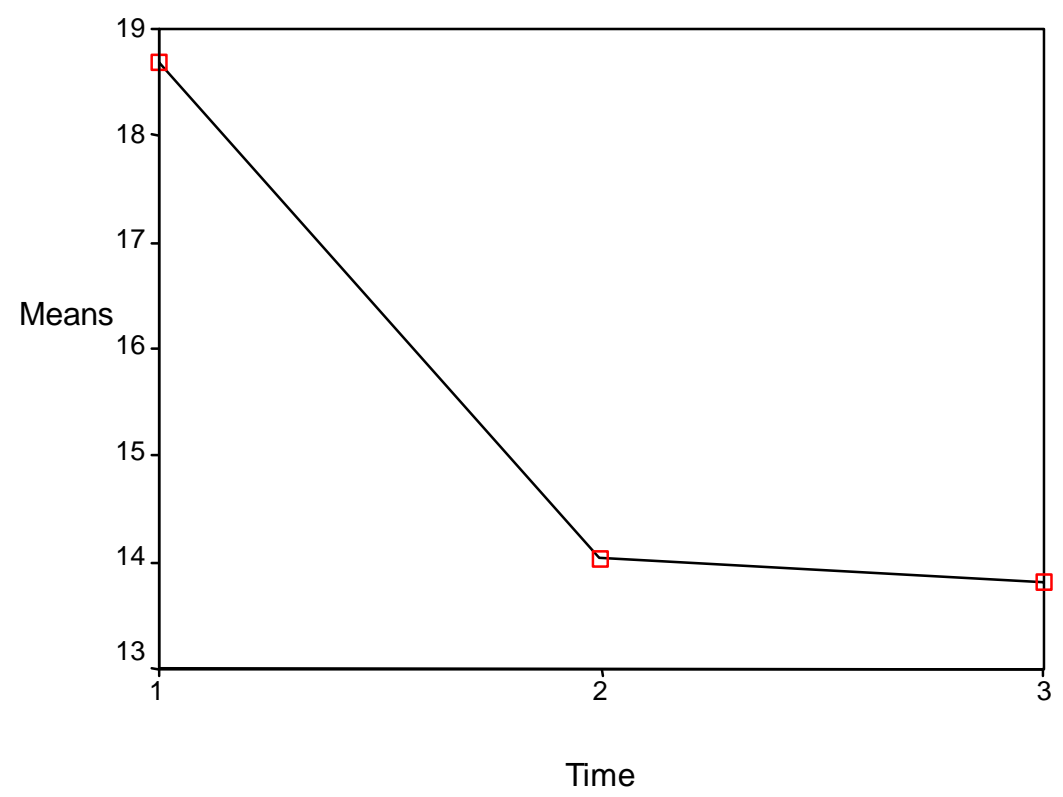


Figure 3 Estimated marginal means of Police Charges data Times 1 and 2, for Intervention and Comparison Group

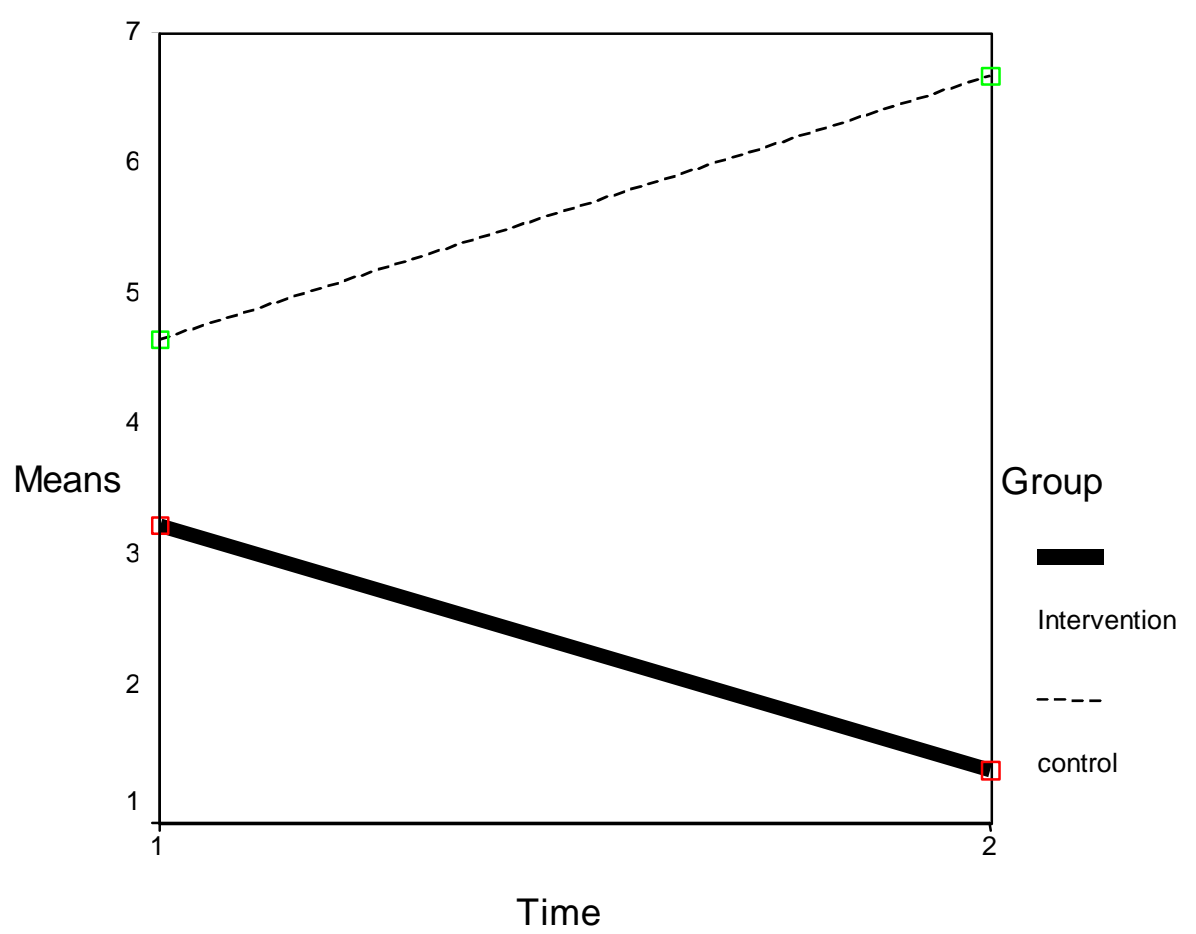

